\title{
Continuing professional development for doctors in accident and emergency
}

\author{
H R Guly
}

Most learning in accident and emergency (A\&E) occurs during normal work. It is a rare week that I do not see a condition I have never seen before and every follow up, whether it be a patient returning to the clinic or visiting a patient in the intensive care unit or postmortem room, is a learning opportunity. Referrals to colleagues and chance discussions about patients over lunch are often educational, as are regular meetings with radiologists and intensivists. For those who do them, even medicolegal reports may help to clarify ideas on prognosis (and psychology). However, doctors and other professional people should not just learn by osmosis, but have a responsibility to devote time specifically to education and development. The responsibility for a junior doctor's postgraduate medical education is shared with their educational supervisor and programme director but for doctors in career posts, including consultants, associate specialists, staff grade doctors and permanent locums, the responsibility for continuing medical education $(\mathrm{CME})$ is a personal one.

This concept of CME is not new as most doctors have always sought to improve their knowledge and skills throughout their career. Their reasons may have been a recognition of their own shortcomings; as preparation for a new job or just as an intellectual challenge but in the past the decision on whether to do CME, how much to do and what to learn has been left largely to the individual practitioner. However, the importance of CME has been emphasised in recent years and other groups including the government, employers, purchasers, insurers, and patients all want confirmation that a doctor is up to date. Keeping up to date is now accepted as a personal and lifelong professional obligation of all doctors. ${ }^{12}$

All doctors, including those in nonconsultant posts, have responsibilities over and above the treatment of patients. For almost all doctors, these responsibilities include audit, supervision of junior colleagues, teaching junior doctors, nurses, and paramedics and some management. Some take on additional responsibilities such as research, undergraduate teaching, organising courses, becoming a clinical tutor, or the greater management responsibilities of a clinical or medical director. These additional responsibilities tend to increase during a doctor's career and require additional education and training. Continuing professional development (CPD) is a term recognised by all professions and covers all training needs including CME. My aim in this paper is to discuss CPD as it affects $A \& E$.

\section{Continuing professional development}

CPD has been defined by the Department of Health as "a process of lifelong systematic learning for all individuals and teams which meets the needs of patients and delivers the health outcomes and healthcare priorities of the NHS and which enables professionals to expand and fulfil their potential". ${ }^{3}$

Note that not only do we have a personal responsibility to keep up to date but, because we work in a team, we have a responsibility to ensure that our team keeps up to date.

The immediate aims of CPD are:

- To maintain knowledge and skills

- To improve existing competencies

- To develop new competencies

but the eventual aim of CPD must be to improve patient care. Thus CPD should lead to improved performance and improved outcomes.

CPD is essential for all doctors and is not about weeding out those who are incompetent or poorly performing, though a doctor under investigation for poor performance will doubtless be asked about how they have kept up to date via CPD.

The easiest way to monitor personal CPD is with a credit based system in which credits are gained for educational activity. This is the system used in most of Europe including the United Kingdom. One credit is given for every hour of educational activity and a doctor is expected to achieve an average of 50 credits per year over a five year period with at least half being obtained through clinical subjects. This method is easy to administer, it is measurable and verifiable. Note that this 50 hours should be time devoted specifically to education and is over and above the learning that occurs on the job. Reading is also important and probably is the second most important educational activity after clinical experience. Unfortunately reading cannot be verified but the fact that it cannot be counted towards the 50 credits per year does not diminish its importance. All doctors are expected to spend time in reading over 
and above the 50 hours of CPD and 100 hours of reading per year has been recommended.

Doctors who have always had pride in keeping up to date resent the bureaucracy that insists on keeping a diary of CPD and filling in an annual return. Let me reassure them that nobody is more aware of the shortcomings of the present system than those responsible for its administration within each college and faculty. While the credit system may guarantee attendance at meetings, it does not guarantee learning. Even if one learns something valuable, there is no evidence that it is put into practice and certainly no evidence that it improves patient care. Much CPD is based on increasing knowledge whereas what is frequently needed is improved skills. Even improved skills do not automatically lead to improved performance.

\section{How can CPD be improved?}

Too often, CPD credits are obtained doing what is enjoyable, for example, the annual British Association for A\&E Medicine conference or by collecting those that are easy to obtain, for example, the regular hospital staff round. While there is nothing wrong with these activities, if CPD to be effective in improving patient care, it must be organised around what the doctor needs rather than what is enjoyable or available. There is no benefit in doing CPD that you do not need, for example, attending a lecture where you know the subject better than the lecturer or, for an $\mathrm{A} \& \mathrm{E}$ doctor, learning about the finer details of cancer chemotherapy. On the other hand, if I have educational needs that are not met, then I am a worse A\&E doctor as a result.

How can educational needs be defined?

Every doctor's educational needs are different: defining these must start with an appraisal. This can occur as peer review or with the line manager. Junior doctors are already appraised regularly and appraisal will soon be routine for all doctors. Needs should not be looked at in isolation or they will come to be seen in a negative way, as failings. An appraisal of an individual taking into consideration their present post, career plans, and interests should define their strengths and competences as well as their CPD needs. Everybody recognises that there are some areas where they are weak or in which they lack confidence and these need to be tackled. Another way is to determine CPD needs from a diary of, say, 100 consecutive consultations. This may demonstrate needs as varied as learning about ligamentous injuries of the wrist, through lack of confidence in paediatric resuscitation to learning the best way to teach chest drain insertion. A mentor may be able to see needs that you do not recognise yourself including such skills as assertiveness and time management. You need to satisfy any requirements of your professional body. At present there are no specific requirements (other than the need to accumulate 50 credits) but many doctors in A\&E feel that they should retain provider status in the main life support courses. External pressures on the department may also determine CPD needs. Regular delays in finding ITU beds may necessitate $\mathrm{A} \& \mathrm{E}$ doctors updating their intensive care skills so that patients can receive full care while they are detained in A\&E; an audit showing poor door to needle time may indicate that thrombolysis be given in $\mathrm{A} \& \mathrm{E}$ and this may produce a learning need. Knowing that you are about to be appointed a clinical director should stimulate some management training. Someone with a clinical or research interest in a topic will need to attend the annual meeting of that subspecialty to keep up to date. It is also important to keep abreast of developments in other specialties, especially with the common diseases that may be present coincidently in patients attending A\&E. Although CPD is the responsibility of the individual, others, particularly employers, are entitled to a say (particularly if they are paying for it). For example, if there have been several complaints about a person's communication skills, it seems reasonable that a chief executive can insist that they attend a course on breaking bad news before they are granted expenses to attend an international conference. If management want the A\&E department to take over the care of a category of patients (for example, head injuries), they will need to provide the training that is required for this.

Having determined needs, you can address wants. These will usually be of relevance to a person's present or future career but as long as you have fulfilled your needs, there may be value in a short course of no direct relevance (for example, on the history of medicine or aviation medicine) for professional refreshment (though you can debate who should pay for this). Improving morale can improve performance. It is, of course, essential that all clinicians continue with medical education and do not allow all education time to be used up with non-clinical CPD. This may be difficult for those with a major managerial role but patients are entitled to know that their doctor is as up to date clinically as in reading a balance sheet. A profile of competences and CPD needs should be written down.

\section{Personal development plan}

Having determined what CME is needed, you need to plan how it can be achieved by drawing up a personal development plan. There is no right and wrong way to learn but the method must be matched to the topic. You may have identified a need to provide a better service to alcoholics in A\&E and thus a need to know more about alcoholism. To learn about alcoholism you can attend lectures or turn to a textbook but to learn about the problem in $\mathrm{A} \& \mathrm{E}$, you probably need to read original papers. Learning which alcoholics the psychiatrists feel they can help needs no more than talking to the local expert but learning to counsel alcoholics cannot be done without practice and may need attendance at a specialist clinic. To learn how well you are dealing with alcohol problems requires audit and to determine how effective $\mathrm{A} \& \mathrm{E}$ interventions can be, may need a research project. A visit to a 
Continuing professional development

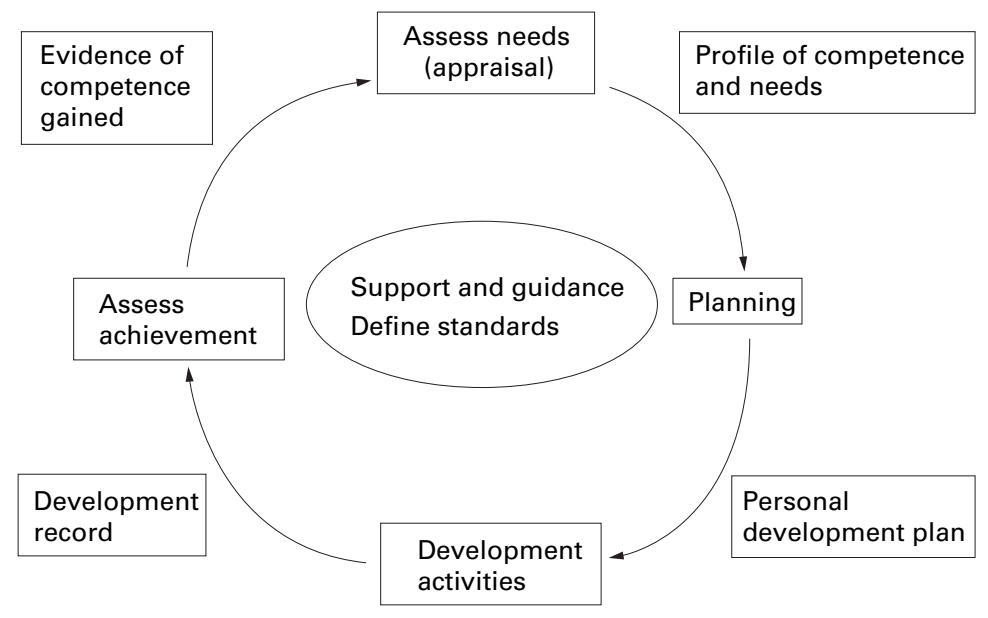

Figure 1 CPD cycle and documentation.

department that has a reputation for dealing with alcohol problems is obviously educational. You cannot learn medicine without seeing patients and there may be no better way of learning about alcohol problems in $\mathrm{A} \& \mathrm{E}$ than to set up a clinical service for these patients, learning and seeking advice as you go along.

In the above example, I have indicated that much CPD can occur by means of everyday work experience, reading and professional contacts but some CPD requires the use of other resourses including courses, conferences, higher degrees, and distance learning. Almost all hospital trusts have training departments running courses on generic skills such as management, interviews skills, information technology, etc. These are frequently underused by doctors. CPD planning will need to take into consideration constraints such as finance and time.

Next you should undertake the development activities that have been planned, and keep a record of them.

Having undertaken development activities, you should assess them and the effect they have had on your competencies. For some activities (for example, a short university course or a life support course) a pass mark may give objective evidence of achievement and in other circumstances there has been a benefit if you have gained a skill that you did not previously have (for example, intraosseous infusion) or gained confidence. On other occasions you can only assess activities as having gained greater knowledge or as ticks against your personal development plan. A useful way of consolidating CPD activities is to present the lessons learnt at a departmental meeting. This can then be CPD activity for others (even if it does not fit into their personal development plan). An assessment of the value of an activity may also be useful for others planning to do the same course.

Lastly, having undertaken a year's programme of CPD, you need to plan for the next year. With any system of CPD, there needs to be a body to define the standards required of practitioners, to monitor people and to ensure quality of educational courses, keep a register of courses, etc. Such a body may also run educational activities itself. In $\mathrm{A} \& \mathrm{E}$ that body is the faculty.

This scheme for CPD conveniently forms a cycle as shown in fig 1 .

\section{The future}

Firstly, the specialty must define the standards required of A\&E specialists and develop a system of appraisal. This will need wide discussion but certification in life support has been suggested as a requirement for all in acute specialties. ${ }^{4}$ The General Medical Council has indicated that continuing educational activity and wider professional development will form the basis of local performance profiling that will be at the heart of revalidation, ${ }^{5}$ This profile will almost certainly be drawn up after an appraisal but the exact form of appraisal has to be decided. When every doctor has a personal development plan based on an annual appraisal, there will be less need to count hours of educational activity and the somewhat artificial distinction between internal and external CME can go. If, at appraisal, doctors can demonstrate that they have met all the needs identified at the previous year's appraisal and fulfilled the requirements of their college, then they will have fulfilled their CPD requirement without counting hours. This will allow much of the reading and informal visits to other units that cannot presently be verified by a college or faculty, to be counted towards CPD.

Conflict of interest: none.

Funding: none.

1 Toghill P. Continuing medical education: where next? BMf 1998;316:721-2.

2 General Medical Council. Good medical practice. London: GMC, 1998.

3 Department of Health. A first class service: quality in the NHS. London: Department of Health, 1998.

4 Bhaskarabhatla VMK. Every hospital must improve inhospital resuscitation. BMF 1999;318:1421-2.

5 General Medical Council. General Medical Council News. Issue 5. London: GMC, 1999.

\section{Advance notice}

John Heyworth's tenure as editor of the fournal of Accident E Emergency Medicine will finish in 2000. The post will be formally advertised in the BMF and Lancet in January. 